\title{
Evaluation of aqueous and ethanol extracts of Cyperus rotundus L. on sexual behaviours and reproductive fitness in Drosophila melanogaster
}

\author{
Nattapong Wongchum ${ }^{1,2}$, Ananya Dechakhamphu ${ }^{3,4}$, Saran Chaweerak ${ }^{3}$, \\ Somchai Pinlaor ${ }^{5}$, Alongklod Tanomtong ${ }^{1 *}$ \\ 1 Department of Biology, Faculty of Science, Khon Kaen University, Khon Kaen, Thailand \\ 2 Biology Program, Faculty of Science, Ubon Ratchathani Rajabhat University, Ubonratchathani, Thailand \\ 3 Thai Traditional Medicine Program, Faculty of Thai Traditional and Alternative Medicine, Ubon Ratchathani Rajabhat University, Ubonratchathani, \\ Thailand \\ ${ }^{4}$ Aesthetic Sciences and Health Program, Faculty of Thai Traditional and Alternative Medicine, Ubon Ratchathani Rajabhat University, Ubonratchathani, \\ Thailand \\ 5 Department of Parasitology, Faculty of Medicine, Khon Kaen University, Khon Kaen, Thailand
}

\begin{abstract}
Cyperus rotundus L. has been used in Ayurvedic and Egyptian folk medicine as an aphrodisiac, no experimental prove has been confirmed for this affirmation. In this study, we aimed to evaluate aqueous and ethanol extract of $C$. rotundus L. on sexual behaviors and reproductive fitness in Drosophila melanogaster. $C$. rotundus was extracts in water (WCE) and ethanolic (HECE). Their extracts were supplemented in diets in $D$. melanogaster. The results revealed that the 5 and $10 \mathrm{mg} / \mathrm{mL}$ HECE treatment significantly decreased the duration time of mating latency, significantly prolonged the copulation duration and produced the maximum number of eggs laying of Drosophila, particularly at $10 \mathrm{mg} / \mathrm{mL}$ HECE supplemented diet. Moreover, as to fertility, supplementation with 5 and $10 \mathrm{mg} / \mathrm{mL}$ HECE in Drosophila significantly increased the number of progenies produced from the mated females. In contrast, 5 and $10 \mathrm{mg} / \mathrm{mL}$ WCE treatment didn't have effect on the duration time of mating latency and the number of progenies in Drosophila compared to the untreated controls. In conclusion, an ethanolic extract of $C$. rotundus exhibits potential of sexual behaviors and reproductive fitness in Drosophila. Our finding might contribute to the potential pharmacological effect of $C$. rotundus ethanol extract as aphrodisiac agent.
\end{abstract}

\section{Keywords:}

Cyperus rotundus L., Aphrodisiac, Drosophila melanogaster, Reproductive fitness

\section{INTRODUCTION}

Sexual dysfunction or sexual disorder is one of the significant health problems that affects both males and females. Sexual dysfunction can be a cause of infertility in both genders ${ }^{1}$, which might associate with a decreasing birth rate around the world. The number of infertile couples is increasing worldwide. In 2010, 1.9\% of women aged 20-44 years who wanted to have children were unable to have their first live birth (primary infertility), and $10.5 \%$ of women with a previous live birth were unable to have an additional live birth (secondary infertility) ${ }^{2}$. For males, erectile dysfunction (ED) has been marked as the most common sexual disorder. A study on global male sexual disorder revealed that the global prevalence of $\mathrm{ED}$ was $3-76.5 \% \%^{3}$. It has been reported that the intervention by aphrodisiac agents is one of the most complaints in male patients who suffer with sexual disorders ${ }^{4}$. Sildenafil citrate is a standard drug that is widely used as an aphrodisiac to improve the sexual ability of males. However, several side effects such as loss of accommodation due to blurred vision, urinary tract infection, stomach disorder, and nasal congestion have been reported ${ }^{5}$.

\section{*Corresponding author:}

*Alongklod Tanomtong alotan@kku.ac.th 
Nowadays, the researchers are searching for aphrodisiac agents from natural compounds because of their efficacy, accessibility, affordability, and minimal side effect ${ }^{6}$. Several medicinal plants used as aphrodisiacs have been reviewed ${ }^{7,8}$.

Cyperus rotundus L. or purple nutsedge is a plant of the Cyperaceae family. This plant is widely distributed in tropical and subtropical regions worldwide? The tuber of this plant has been used in traditional medicine in many regions worldwide ${ }^{10}$. The results from in vitro and in vivo studies suggest that $C$. rotundus's extracts are the potential bioactive substances for the prevention and treatment of many diseases ${ }^{11}$. The pharmacological properties of $C$. rotundus included antioxidant ${ }^{12}$, wound healing ${ }^{13}$, anti-microbial ${ }^{14}$, anticonvulsant ${ }^{15}$, anti-allergy ${ }^{16}$, anti-hyperglycemic ${ }^{17}$, cardioprotective and anti-hyperlipidemic ${ }^{11}$, anti-viral activity ${ }^{18}$, anti-inflammation ${ }^{19}$, anti-obesity ${ }^{20}$, anti-diarrhea ${ }^{21}$, and anti-pyretic ${ }^{22}$. According to aphrodisiac property, the hot water extract of its tuber has been used in Ayurvedic and Egyptian folk medicine ${ }^{10,23}$. In addition, the tuber of C. rotundus has been described to use as spermatogenic property $^{24}$. Although the tuber of $C$. rotundus is described as an aphrodisiac, there is no experimental prove confirming this affirmation.

For aphrodisiac agent testing, Drosophila melanogaster or fruit fly is one of the most effective models for the evaluation of natural compounds. This model organism shares a large amount of conserved biological pathways and disease-causing genes with humans ${ }^{25,26}$. D. melanogaster is a respectable model for studying sexual behaviors because of its behavioral plasticity ${ }^{27}$. Also, the fruit fly has evidenced to be a fast and costeffective model system. Because of it has short lifespan, the low number of chromosomes, high fecundity, and easy to handle ${ }^{25}$. Hence, D. melanogaster was used as a model to study the aphrodisiac property of $C$. rotundus in the different solvent extracts.

In this study, we intended to test whether water and ethanolic extracts of $C$. rotundus exhibit sexual behaviors and reproductive fitness in D. melanogaster, a respectable model for studying sexual behaviors. The effects of $C$. rotundus extracts on the fecundity and fertility of $D$. melanogaster was also investigated. The study might have valuable for alternative medical plant as aphrodisiac agent.

\section{MATERIALS AND METHODS}

\subsection{Preparation of $C$. rotundus extract}

C. rotundus tuber was collected in Singburi Province, Thailand during April 2019. Plant materials were dried in a hot air oven at $50^{\circ} \mathrm{C}$ for 48 hours and ground into a fine powder. A hundred grams of fine powder was extracted with $500 \mathrm{~mL}$ distilled water by decoction using round bottom flask at $95 \pm 0.7^{\circ} \mathrm{C}$ for 30 minutes. The extracts were filtered with a No.1 Whatman filter paper, and concentrated by using a lyophilizer at $-110^{\circ} \mathrm{C}$. The dried materials were stored at $-20^{\circ} \mathrm{C}$ until use.

Another 100 grams of powder was extracted with $500 \mathrm{~mL} 70 \%$ ethanol by using the maceration method for 7 days at ambient temperature $(25-30)^{\circ} \mathrm{C}$. The extracts were obtained by filtration (Whatman filter paper 40) and concentrated on a rotary evaporator (Buchi R-210, Flawil, Switzerland). The derived extracts were stored at $-20^{\circ} \mathrm{C}$ until use.

\subsection{C. rotundus extract analysis}

The analysis was performed on high-performance liquid chromatography (Water 486 model with UV/Vis detector). The HPLC separation was performed on a Hypersil C18 column $(150 \times 4.5 \mathrm{~mm}, 5 \mu \mathrm{m})$ and quantified on a UV detector at 272 and $336 \mathrm{~nm}$. The mobile phase was an isocratic of $0.1 \%$ phosphoric acid: $\mathrm{ACN}(45: 55)$. The flow rate was $1 \mathrm{~mL} / \mathrm{min}$. The peaks were identified according to the retention time of standards

\subsection{Culturing of Drosophila}

The wild type D. melanogaster strain was obtained from the Department of Biology, Khon Kaen University. The flies were cultured in a standard wheat cream agar media seeded with yeast granules and maintained under the laboratory condition at a temperature of $25 \pm 1.2^{\circ} \mathrm{C}$ of relative humidity $70-80 \%$ on a $12: 12$ light/dark cycle with survivors transferred to fresh food vials every 2 days. The animal study protocol was approved by The Animal Ethic Committee of Ubon Ratchathani Rajabhat University, Thailand (Ethical Clearance No. AN63008).

\subsection{Sexual behavior assay}

To evaluate the aphrodisiac effect of water (WCE) and ethanolic (HECE) extracts of $C$. rotundus, the analysis of sexual behavior patterns was used in the study. The method was modified from the previously described with some slightly modification ${ }^{28,29}$. In order to obtain virgin females and bachelor males, the pupa stage of flies was isolated into a separated vial and maintained them separately in standard media for 5 days (the flies enclosed within 5 hours after isolation). After that, 20 flies of both genders were starved for 2 hours and fed for 40 hours with WCE or HECE extracts at a concentration of 5 and $10 \mathrm{mg} / \mathrm{mL}$ (mixed to the diet). For observation of the aphrodisiac effect, the mating latency (time between the introduction of males and females into the mating chamber and initiation of copulation of each pair) and copulation duration (time between initiation and termination of copulation of each pair) were investigated. The latency to initiate courting 
and the occurrence of specific behaviors (tapping, wing vibration, licking, and attempting copulation) were recorded. The courtship index (CI) was calculated by dividing the time spent in courtship divided by the total time until copulation. The experiments were done in the morning hours between 6.00-8.00 AM. The data were expressed as mean \pm SD.

\subsection{The reproductive fitness assays}

The fecundity was analyzed by counting the number of eggs laid by mated paired Drosophila for ten days after mating. The females of mated Drosophila were individually transferred into a vial containing a standard diet and allowed to lay eggs for 24 hours. After 24 hours, the number of eggs laid by Drosophila from each experimental group was counted using a stereomicroscope. The mated Drosophila were transferred to the new food vial diet every day. The data of ten days were pooled to calculate the number of eggs per Drosophila. The data were expressed as mean \pm SD.

The fertility was analyzed by counting the total number of Drosophila that emerged from each vial. All vials collected from ten consecutive changes were kept and the new emerged Drosophila were counted until no fly emerging. The data of total number of new flies from the same experimental group were pooled and the number of flies per female were calculated. The data were expressed as mean \pm SD. The experiment was performed in triplicate.

\subsection{Statistical analysis}

Statistical analysis of the data was done with the SPSS 23.0 (SPSS Inc., Chicago, USA). The comparison between means was analyzed using One-Way ANOVA. Differences were considered significant when $P<0.05$. For all assays, $P$ values for levels of significance are symbolized as $*<0.05$, and $* *<0.01$.

\section{RESULTS}

\subsection{Phytochemical analysis}

The HPLC chromatogram of $C$. rotundus extract was shown in Figure 1. It was found that HECE used in this study contained quercetin $(0.252 \mathrm{ug} / \mathrm{mg})$, gallic acid (0.499 ug/mg) and tannic acid (7.939 ug/mg). However, these phytochemical compounds were not detected in WCE.

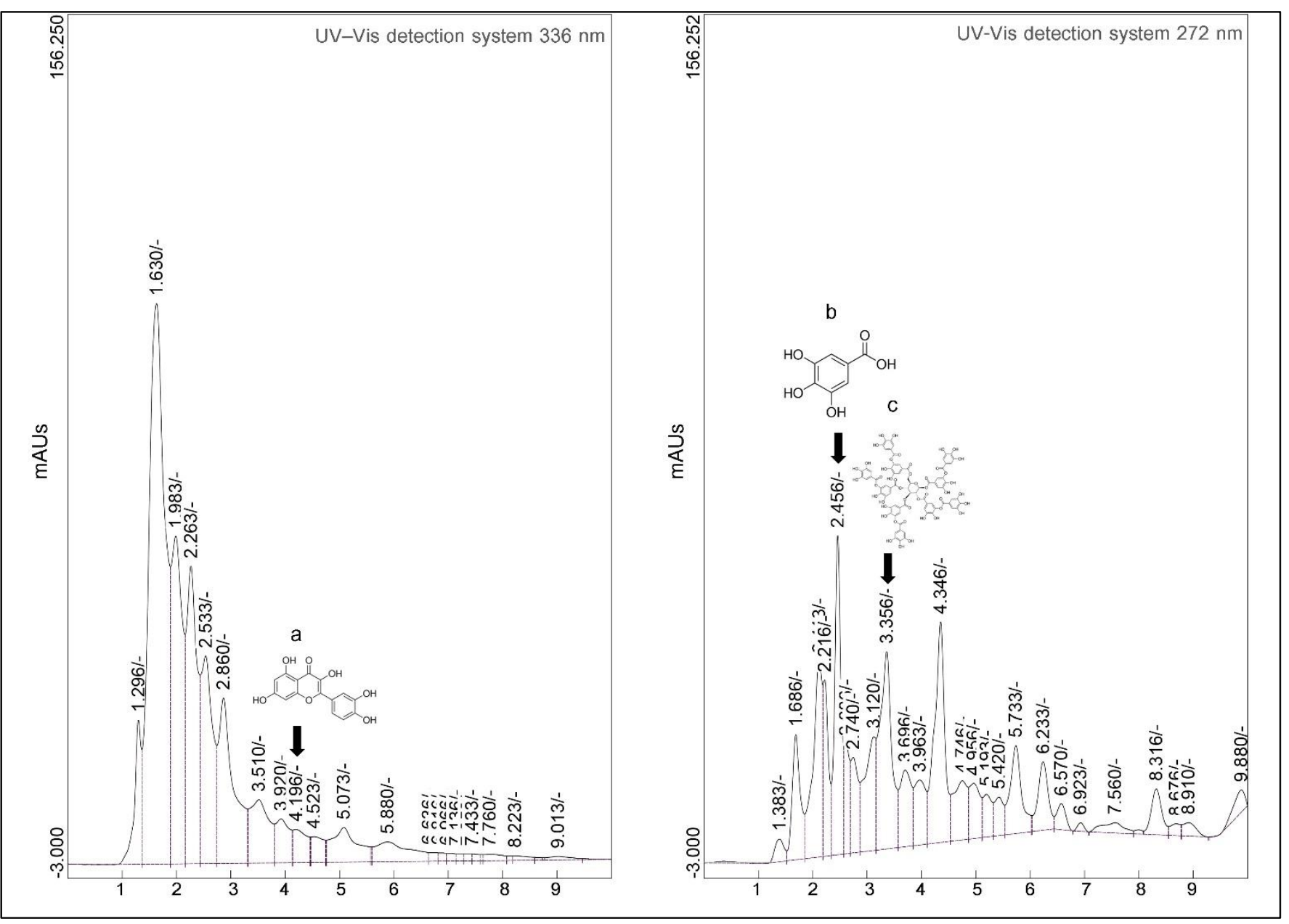

Figure 1. Chromatogram of C. rotundus extract: (a) quercetin, (b) gallic acid and (c) tannic acid. 


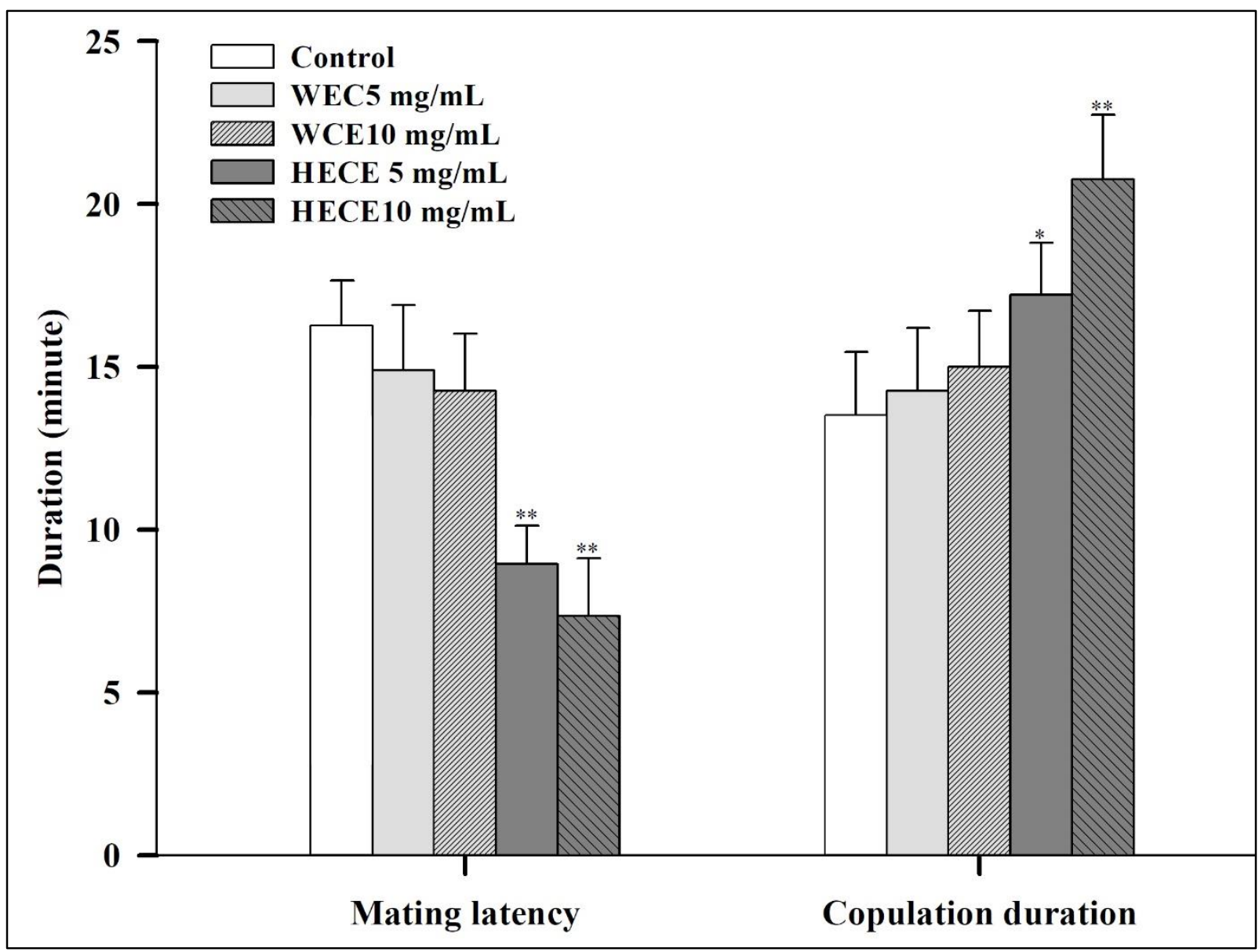

Figure 2. Effect of $C$. rotundus extracts on mating latency and copulation duration in D. melanogaster $(* ; p<0.05$, and $* * ; p<0.01)$.

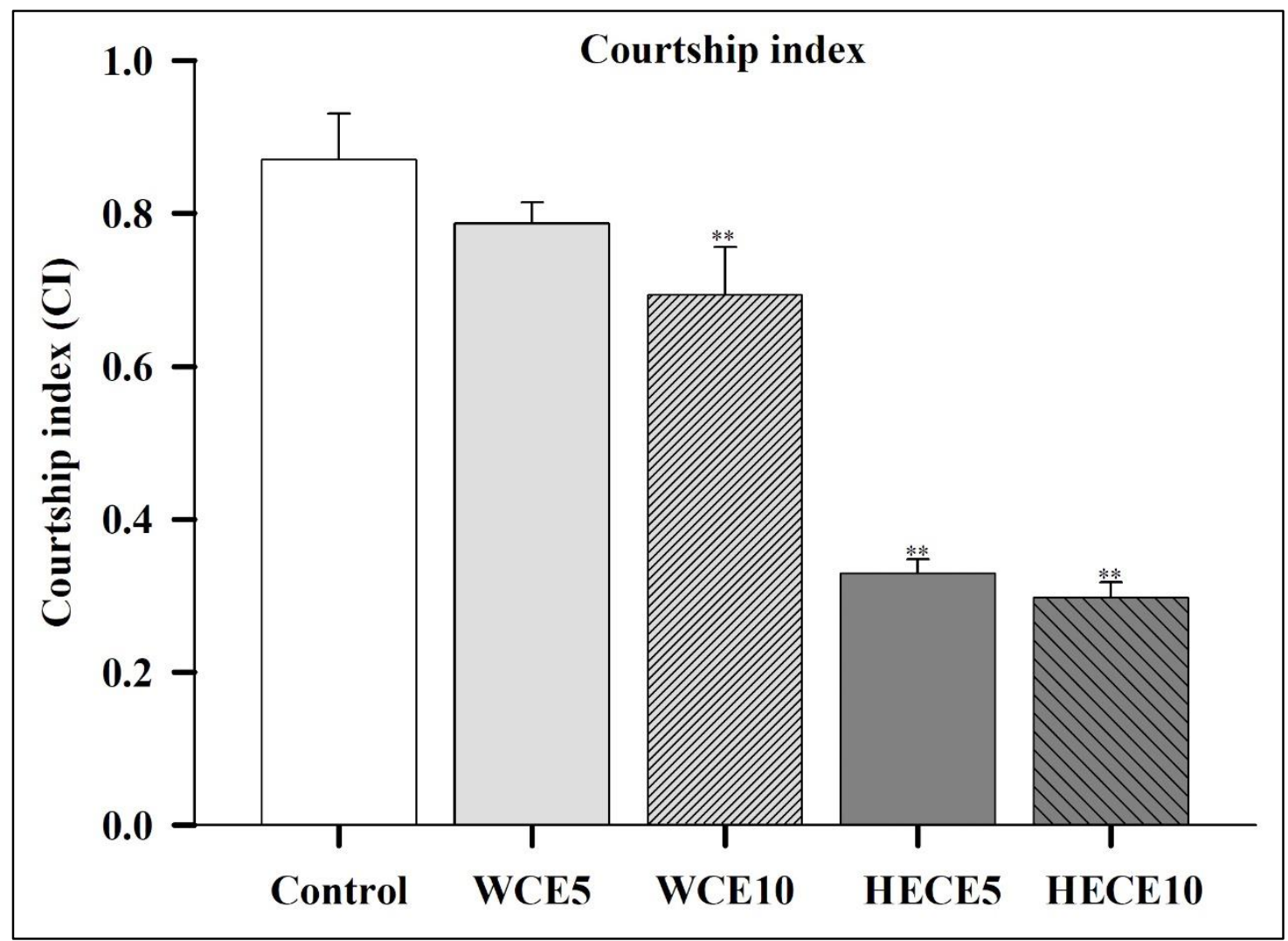

Figure 3. Effect of C. rotundus extracts on courtship index in D. melanogaster (**; $p<0.01$ ). 


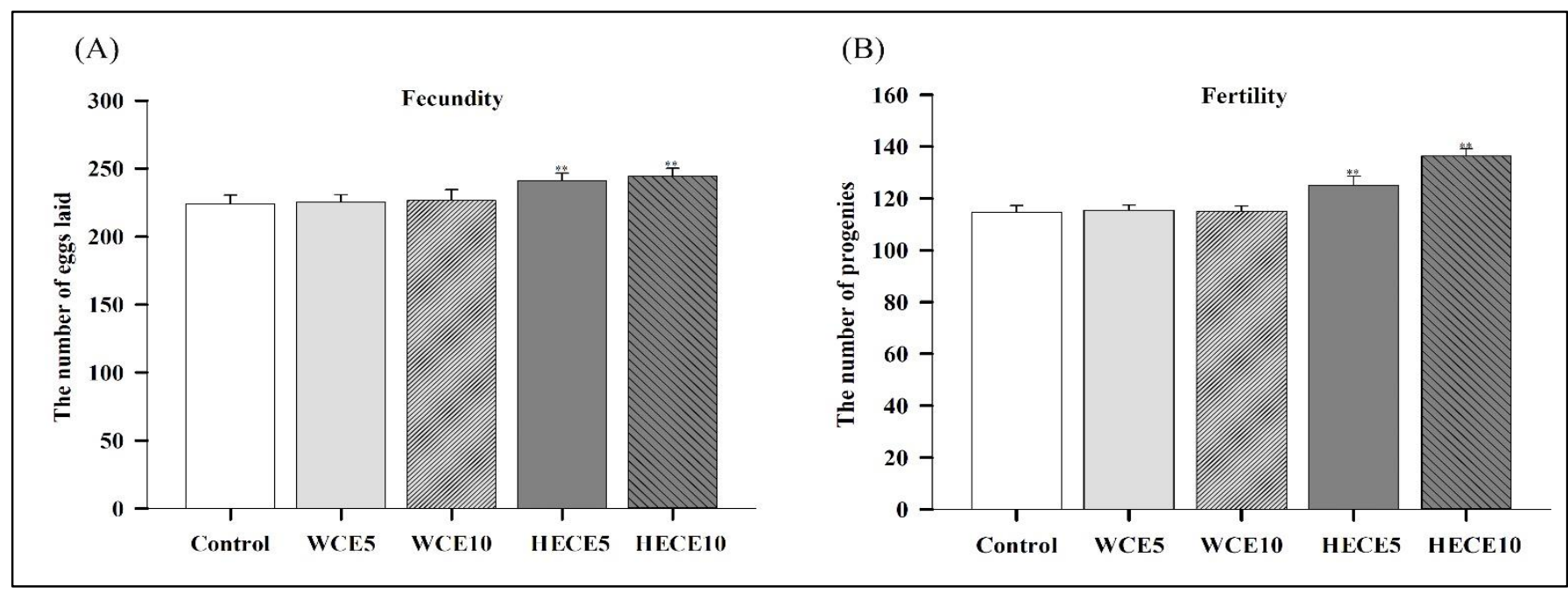

Figure 4. The effect of $C$. rotundus extracts on the productive fitness of D. melanogaster. (A) Number of eggs laid. (B) Number of progenies $(* * ; p<0.01)$.

\subsection{Effect of $C$. rotundus extracts on the sexual behavior of Drosophila}

The effect of $C$. rotundus extracts on the sexual behavior of Drosophila is shown Figure 2. The minimum duration time for mating was observed in Drosophila treated with a diet containing ethanolic extract of HECE at $10 \mathrm{mg} / \mathrm{mL}$. Results from the One-Way ANOVA test showed that the 5 and $10 \mathrm{mg} / \mathrm{mL}$ HECE treatment significantly decreased the duration time of mating latency of Drosophila $(8.95 \pm 1.16$ and $7.35 \pm 1.77 \mathrm{~min}$, respectively compared with the control group (16.25 $1.39 \mathrm{~min}$ ). No significant difference was found in 5 and $10 \mathrm{mg} / \mathrm{mL}$ WCE treatment Drosophila when compared with the control group.

The copulation duration of Drosophila with or without treatment by $C$. rotundus was also investigated as shown in Figure 2. Treatment with 5 and $10 \mathrm{mg} / \mathrm{mL}$ HECE significantly prolonged the copulation duration of Drosophila (17.20 \pm 1.60 and $20.75 \pm 1.98 \mathrm{~min}$, respectively) compared with the control group (13.50 \pm 1.95 min). Treatment by 5 and $10 \mathrm{mg} / \mathrm{mL}$ WCE in Drosophila had a trend towards prolonging the copulation duration without statistically different compared to untreated controls.

As shown in Figure 3, the mean of the courtship index was significantly lower in Drosophila fed with the diet containing 5 and $10 \mathrm{mg} / \mathrm{mL}$ HECE $(0.33 \pm 0.02$ and $0.23 \pm 0.02$, respectively) than in untreated control $(0.87 \pm$ 0.06). WCE treatment was dose dependent effect on the courtship index in Drosophila at a concentration of 10 $\mathrm{mg} / \mathrm{mL}$, but was not $5 \mathrm{mg} / \mathrm{mL}$ WCE compared to untreated controls.

\subsection{Effect of $C$. rotundus extracts on the reproductive fitness of Drosophila}

The effect of $C$. rotundus extracts on the produc- tive fitness of Drosophila is shown in Figure 4. The maximum number of eggs laid was observed in the Drosophila fed with a diet containing $10 \mathrm{mg} / \mathrm{mL}$ HECE. Treatment of $5 \mathrm{mg} / \mathrm{mL}$ HECE also significantly increased in the number of eggs laid in Drosophila $(240 \pm 5.74$ and $244.35 \pm 5.85$, respectively) compared to untreated control (224.25 \pm 6.11$)$. In contrast, WCE treatment at the concentration of 5 and $10 \mathrm{mg} / \mathrm{mL}$ was not statistically different from untreated controls. As to fertility, supplementation with 5 and $10 \mathrm{mg} / \mathrm{mL}$ HECE in Drosophila significantly increased the number of progenies produced from the mated females with dose-dependent manner (125.05 \pm 3.59 and $136.40 \pm 2.82$, respectively) compared to untreated control (114.55 \pm 2.70$)$. In contrast, no statistical difference in the number of progenies in Drosophila was observed after WCE at the concentration of 5 and $10 \mathrm{mg} / \mathrm{mL}$ supplemented diet compared to the untreated controls.

\section{DISCUSSION}

Numerous medicinal plants have historically been known as aphrodisiacs, including tuber of $C$. rotundus, however, the experiment proves this is limited. Here, we demonstrated the different extraction solvents by water and ethanol of $C$. rotundus on sexual behaviors and reproductive fitness in Drosophila. This animal is an attractive model to study behavior because of its complex behavioral repertoires and sensory system $^{30,31}$. The expression of sexual behavior of the Drosophila is comparable to that of mammals because Drosophila receptors have been shown to mediate similar behavioral responses to the same effector pathway as mammalian $^{32}$. Therefore, this animal model can be used to analyze aspects of human disease-related behaviors ${ }^{33}$.

Our results revealed that ethanol extract of $C$. rotundus exhibited more potential than water extract on sexual behaviors and reproductive fitness in Drosophila. 
These finding was in agreement with many previous reported in the Drosophila model that aphrodisiac agents exhibit a decrease in mating latency while increasing copulation duration ${ }^{34,35}$.

The main parameters for studying sexual behavior in Drosophila are mating latency and copulation duration. These parameters associate with the sexual desire of males. It has been clearly demonstrated that a male with strong sexual desire reacts quickly in the presence of a female $e^{36,37}$. Copulation duration indicates the sexual performance and associates with the reproductive fitness of Drosophila. The duration of copulation positively relates to the number of sperm transferring from male to female ${ }^{35}$. The extension of copulation duration improves the fitness of both males and females. As shown in Figure 1, reduced the duration time for mating latency and courtship index indicates that supplementation of $C$. rotundus extract could stimulate sexual desire in the Drosophila. In addition, an improvement in sexual performance was detected in Drosophila fed with $C$. rotundus extract through prolonged the copulation duration, which was agreement with the previous reports ${ }^{35,36}$.

Fecundity and fertility are a significant parameter for evaluating fitness in Drosophila. These two parameters influence the reproductive fitness of females and can be influenced by environmental factors ${ }^{38}$. In this study, our results showed that a significant increase of fecundity and fertility of Drosophila fed with $C$. rotundus extract (Figure 3) were supported to the effect of supplementation extract for improving the reproductive fitness.

The molecular mechanism by which $C$. rotundus extract exhibits an aphrodisiac effect and improves reproductive fitness is still unclear. The possible explanation for these properties involves its phytochemical contents. Based on our results showed that the more significant ethanolic extract gave more than water extract, suggesting that compounds that soluble in ethanol may be the primary active ingredients. The active compounds of $C$. rotundus are well studied ${ }^{39}$. We primarily considered that the polyphenols or flavonoids existing in our extract might demonstrate its effects. Our results showed that HECE used in this study contained gallic acid, quercetin, and tannic acid. Zhou and $\mathrm{Fu}(2012)$ have reported that $C$. rotundus rhizomes contain quercetin, kaempferol, luteolin, ginkgetin, and isoginkgetin ${ }^{40}$. Moreover, polyphenolic substances, including leucocyanidin, leucoyanidinglucoside, catechine and chlorogenic acid were also identified in tubers of C. rotundus ${ }^{41}$. Although the direct proof does not exist in the Drosophila model, a previous study revealed that supplementation with an extract of $C$. esculent tubers that contains quercetin could stimulate sexual motivation and improve sexual performance in male rats ${ }^{42}$. In rats, quercetin treatment also showed to improve sexual behavior, sperm quantity, and quality in streptozotocininduced diabetic erectile dysfunction ${ }^{43}$. In addition, Tamarindus indica extract containing gallic acid as a component has been proven to increase the aphrodisiac potential in Wistar rats ${ }^{44}$. Based on the results from previous studies and this study, quercetin and gallic acid contained in the $C$. rotundus extract may be one of the key agents for improving reproductive fitness.

Taken together the results from this study and the previous studies contribute to the potential pharmacological effect of $C$. rotundus extract as an aphrodisiac agent. Nevertheless, this study's limitation is the use of the crude extract, which should have to be the purification of $C$. rotundus extract use and test its activity in Drosophila. In addition, further studies in the mammal model are now required to verify the role of C. rotundus extract in aphrodisiac property. Ultimately, the supplementation with $C$. rotundus extract may help to improve sexual function and reproductive fitness.

\section{CONCLUSIONS}

An ethanolic extract of $C$. rotundus exhibits potential of sexual behaviors and reproductive fitness in Drosophila. Our finding might contribute to the potential pharmacological effect of $C$. rotundus ethanol extract as aphrodisiac agent.

\section{ACKNOWLEDGEMENT}

This research was supported by the Royal Thai Government Scholarship (Ministry of Higher Education, Science, Research and Innovation). The authors thank the Faculty of Thai Traditional and Alternative Medicine, Ubon Ratchathani Rajabhat University, for providing instruments. We thank Mr. Jakrapong Thangthong, Plant Taxonomist, Ubon Ratchathani Rajabhat University, for his assistance on plant identification. We thank Assistant Professor Dr. Monthira Monthatong, Department of Biology, Faculty of Sciences, Khon Kaen University, Thailand, for providing the wild-type Drosophila.

\section{Conflict of interest}

The authors declare no conflict of interest.

\section{Funding}

This research was supported by the Royal Thai Government Scholarship (Ministry of Higher Education, Science, Research and Innovation.

\section{Ethics approval}

The animal study protocol was approved by The Animal Ethic Committee of Ubon Ratchathani Rajabhat University, Thailand (Ethical Clearance No. AN63008).

\section{Article info:}


Received November 13, 2020

Received in revised form February 18, 2021

Accepted March 20, 2021

\section{REFERENCES}

1. Starc A, Trampuš M, Pavan Jukić D, Rotim C, Jukić T, Polona Mivšek A. Infertility and sexual dysfunctions: a systematic literature review. Acta Clin Croat. 2019;58(3):508-15.

2. Mascarenhas MN, Flaxman SR, Boerma T, Vanderpoel S, Stevens GA. National, regional, and global trends in infertility prevalence since 1990: a systematic analysis of 277 health surveys. PLoS Med. 2012;9(12):e1001356.

3. Kessler A, Sollie S, Challacombe B, Briggs K, Van Hemelrijck $\mathrm{M}$. The global prevalence of erectile dysfunction: a review. BJU Int. 2019;124(4):587-99.

4. Lindau ST, Schumm LP, Laumann EO, Levinson W, O'Muircheartaigh CA, Waite LJ. A study of sexuality and health among older adults in the United States. N Engl J Med. 2007;357(8):762-74.

5. Lue TF. Erectile dysfunction. N Engl J Med. 2000;342(24):1802-13.

6. Sharma M, Arya D, Bhagour K, Gupta RS. Natural aphrodisiac and fertility enhancement measures in males: A review. Curr Med Res Pract. 2017;7(2):51-8.

7. Chauhan NS, Sharma V, Dixit VK, Thakur M. A review on plants used for improvement of sexual performance and virility. Biomed Res Int. 2014;2014:868062.

8. Ajao AA, Sibiya NP, Moteetee AN. Sexual prowess from nature: A systematic review of medicinal plants used as aphrodisiacs and sexual dysfunction in sub-Saharan Africa. S Afr J Bot. 2019; 122:342-59.

9. Qasim M, Abideen Z, Adnan MY, Ansari R, Gul B, Khan MA. Traditional ethnobotanical uses of medicinal plants from coastal areas. J Coat Life Med. 2014;2(1):22-30.

10. Ross IA. Cyperus rotundus L. In Medicinal Plants of the World: chemical constituents, traditional and modern medicinal uses. New York:Humana Press; 2003. p. 209-26.

11. Hemanth KK, Razack S, Nallamuthu I, Khanum F. Phytochemical analysis and biological properties of Cyperus rotundus $\mathrm{L}$. Ind Crops Prod. 2014;52:815-26.

12. Pal DK, Dutta S. Evaluation of the antioxidant activity of the roots and rhizomes of Cyperus rotundus L. Indian J Pharm Sci. 2006;68(2):256-8

13. Puratchikody A, Devi C, Nagalakshmi G. Wound healing activity of Cyperus rotundus Linn. Indian J Pharm Sci. 2006; 68(1):97-101.

14. Sharma SK, Singh AP. Antimicrobial investigations on rhizomes of Cyperus rotundus Linn. Der Pharm Lett. 2011;3(3):427-31.

15. Shivakumar SI, Suresh HM, Hallikeri CS, Hatapakki BC, Handiganur JS, Sankh K, et al. Anticonvulsant effect of Cyperus rotundus Linn rhizomes in rats. J Nat Remedies. 2009;9(2):192-6.

16. Jin JH, Lee DU, Kim YS, Kim HP. Anti-allergic activity of sesquiterpenes from the rhizomes of Cyperus rotundus. Arch Pharm Res. 2011;34(2):223-8.

17. Tran HHT, Nguyen MC, Le HT, Nguyen TL, Pham TB, Chau VM. et al. Inhibitors of $\alpha$-glucosidase and $\alpha$-amylase from Cyperus rotundus. Pharm Biol. 2014;52(1):74-7.

18. Soltan MM, Zaki AK. Antiviral screening of forty-two Egyptian medicinal plants. J Ethnopharmacol. 2009;126(1):102-7.

19. Chithran A, Ramesh BT, Himaja N. Comparative study on antiinflammatory activity of Cyperus rotundus (L.) using different solvent system in carragenan induced paw edema in albino wistar rats. Int J Phytopharmacol. 2012;3:130-4.

20. Athesh K, Divakar M, Brindha P. Anti-obesity potential of Cyperus rotundus $\mathrm{L}$. aqueous tuber extract in rats fed on high fat cafeteria diet. Asian J Pharm Clin Res. 2014;7(2):88-92.

21. Uddin SJ, Mondal K, Shilpi JA, Rahman MT. Antidiarrhoeal activity of Cyperus rotundus. Fitoterapia. 2006;77(2):134-6.

22. Gupta MB, Palit TK, Singh N, Bhargava KP. Pharmacological studies to isolate the active constituents from Cyperus rotundus possessing anti-inflammatory, anti-pyretic and analgesic activities. Indian J Med Res. 1971;59(1):76-82.

23. Boulos L, El-Hadidi MN. The weed flora of Egypt. Cairo:The American University in Cairo Press; 1984. p. 58.

24. Chevallier A. The Encyclopedia of Medicinal Plants. London: Dorling Kindersley; 1996. p. 1-197.

25. Panchal K, Tiwari AK. Drosophila melanogaster "a potential model organism" for identification of pharmacological properties of plants/plant-derived components. Biomed Pharmacother. 2017;89:1331-45.

26. Pandey UB, Nichols CD. Human disease models in Drosophila melanogaster and the role of the fly in therapeutic drug discovery. Pharmacol Rev. 2011;63(2):411-36.

27. Griffith LC, Ejima A. Courtship learning in Drosophila melanogaster: diverse plasticity of a reproductive behavior. Learn Mem. 2009;16(12):743-50.

28. Spieth HT, RINGO JM. Mating behavior and sexual isolation in Drosophila In: Ashburner M, Carson HL, and Thompson JN Jr, editors. The Genetics and Biology of Drosophila Vol. 3c. New York:Academic Press; 1983. p. 223-84.

29. Hegde SN, Krishnamurthy NB. Studies on mating behaviour in the Drosophila bipectinata complex. Aust J Zool. 1979;27(3):421-31.

30. Hirsch HV, Tompkins L. The flexible fly: experience-dependent development of complex behaviors in Drosophila melanogaster. J Exp Biol. 1994;195:1-18.

31. Griffith LC, Ejima A. Courtship learning in Drosophila melanogaster: diverse plasticity of a reproductive behavior. Learn Mem. 2009;16(12):743-50.

32. Becnel J, Johnson O, Luo J, Nässel DR, Nichols CD. The serotonin $5-\mathrm{HT}_{7}$ Dro receptor is expressed in the brain of Drosophila, and is essential for normal courtship and mating. PLoS One. 2011;6(6):e20800.

33. Nichols CD, Becnel J, Pandey UB. Methods to assay Drosophila behavior. J Vis Exp. 2012;(61):3795.

34. Suchitra G, Shakunthala V. Effect of Glycyrrhiza glabra root extract on behaviour and fitness of Drosophila melanogaster and vestigial wing mutant. Int J Curr Microbiol Appl Sci. 2014; 3(7):1047-54.

35. Pathak P, Prasad BR, Murthy NA, Hegde SN. The effect of Emblica officinalis diet on lifespan, sexual behavior, and fitness characters in Drosophila melanogaster. Ayu. 2011;32(2):279-84.

36. Eastwood L, Burnet B. Courtship latency in male Drosophila melanogaster. Behav Genet. 1977;7(5):359-72.

37. Saleem S, Ruggles PH, Abbott WK, Carney GE. Sexual experience enhances Drosophila melanogaster male mating behavior and success. PLoS ONE. 2014;9(5):e96639.

38. Reed DH, Lowe EH, Briscoe DA, Frankham R. Fitness and adaptation in a novel environment: Effect of inbreeding, prior environment, and lineage. Evolution. 2003;57(8):1822-8.

39. Pirzada AM, Ali HH, Naeem M, Latif M, Bukhari AH, Tanveer A. Cyperus rotundus L.: Traditional uses, phytochemistry, and pharmacological activities. J Ethnopharmacol. 2015;174:540-60.

40. Zhou Z, Fu C. A new flavanone and other constituents from the rhizomes of Cyperus rotundus and their antioxidant activities. Chem Nat Compd. 2013;48(6):963-5.

41. Komai K, Ueki K. Chemical Properties and Behaviour of Polyphenolic Substances in Purple Nutsedge (Cyperus rotundus L.). Weed Technol. 1975;20(2):66-71.

42. Allouh MZ, Daradka HM, Ghaida JHA. Influence of Cyperus esculentus tubers (Tiger Nut) on male rat copulatory behavior. BMC Complement Altern Med. 2015;15:331.

43. Al-Roujayee A. Improvement of sexual behavior, sperm quantity and quality by Quercetin in streptozotocin-induced diabetic erectile dysfunction. Asian Pacific J Reprod. 2017;6(1):6-12.

44. Rai A, Das S, Chamallamudi MR, Nandakumar K, Shetty R, Gill $\mathrm{M}$, et al. Evaluation of the aphrodisiac potential of a chemically characterized aqueous extract of Tamarindus indica pulp. $\mathrm{J}$ Ethnopharmacol. 2018;10(210):118-24. 